\title{
Differential sensitivity of osteoblasts and bacterial pathogens to 405-nm light highlighting potential for decontamination applications in orthopedic surgery
}

\author{
Praveen Ramakrishnan, ${ }^{a}$ Michelle Maclean, ${ }^{b}$ Scott J. MacGregor, ${ }^{b}$ John G. Anderson, ${ }^{b}$ and M. Helen Grant ${ }^{a, *}$ \\ aUniversity of Strathclyde, Department of Biomedical Engineering, Wolfson Centre, 106 Rottenrow, Glasgow, Scotland G4 0NW, United Kingdom \\ bUniversity of Strathclyde, The Robertson Trust Laboratory for Electronic Sterilisation Technologies, 204 George Street, Glasgow, Scotland G1 \\ $1 \mathrm{XW}$, United Kingdom
}

\begin{abstract}
Healthcare associated infections pose a major threat to patients admitted to hospitals and infection rates following orthopedic arthroplasty surgery are as high as 4\%. A 405-nm high-intensity narrow spectrum light has been proven to reduce environmental contamination in hospital isolation rooms, and there is potential to develop this technology for application in arthroplasty surgery. Cultured rat osteoblasts were exposed to varying light intensities and it was found that exposures of up to a dose of $36 \mathrm{~J} / \mathrm{cm}^{2}$ had no significant effect on cell viability (MTT assay), function (alkaline phosphatase activity), and proliferation rate (BrdU cell proliferation assay). High irradiance exposures $\left(54 \mathrm{~J} / \mathrm{cm}^{2}\right)$ significantly affected the cell viability indicating that the effects of 405-nm light on osteoblasts are dose dependent. Additionally, exposure of a variety of clinically related bacteria to a dose of $36 \mathrm{~J} / \mathrm{cm}^{2}$ resulted in up to $100 \%$ kill. These results demonstrating the differential sensitivity of osteoblasts and bacteria to 405-nm light are an essential step toward developing the technique for decontamination in orthopedic surgery. ๑ 2014 Society of Photo-Optical Instrumentation Engineers (SPIE) [DOI: 10.1117/1.JBO.XX.XX.XXXXXX]
\end{abstract}

Keywords: healthcare associated infections; arthroplasty surgery; decontamination; 405-nm light; dose-dependent osteoblast cell damage; bacteria inactivation.

Paper 140288RRR received May 7, 2014; revised manuscript received Sep. 5, 2014; accepted for publication Sep. $11,2014$.

\section{Introduction}

Healthcare associated infection (HAI) affects approximately $10 \%$ of patients admitted to the hospital, and is responsible for over 5000 deaths in the UK annually (Improving Patient Care by Reducing the Risk of Hospital Acquired Infection: A Progress Report, National Audit Office 2004). HAI can be caused by airborne and environmental bacterial contamination which can be transmitted to surgical site wounds either directly from the environment or indirectly via vectors such as healthcare workers' hands. ${ }^{1,2}$ A 405-nm high-intensity narrow spectrum (HINS) light has antimicrobial activity against HAI-related bacterial pathogens including methicillin-resistant Staphylococcus aureus $^{3}$ and, due to the use of visible light wavelengths, this does not pose the same health concerns as those associated with using ultraviolet light. This 405-nm light technology has already been used to develop an environmental decontamination system for the disinfection of air and environmental surfaces, which has been successfully clinically evaluated within isolation rooms at Glasgow Royal Infirmary. ${ }^{4}$

Infection rates following orthopedic arthroplasty surgery are as high as $4 \%$, while the infection rates are even higher after revision surgery, ${ }^{5}$ and the environment and surgical devices have been highlighted as sources of bacterial contamination. ${ }^{6}$

The bactericidal properties of 405-nm light suggest that this may aid in reducing the incidence of infections that arise from environmental contamination during arthroplasty surgery. The toxic effect of $405-\mathrm{nm}$ light on bacterial cells is not replicated

*Address all correspondence to: M. Helen Grant, E-mail: m.h.grant@ strath.ac .uk to the same extent in mammalian cells, and this has been successfully demonstrated in previous studies. ${ }^{7,8}$

If 405-nm light technology was to be promoted for localized disinfection during arthroplasty surgery, the bone would likely be exposed to 405 -nm light during the course of surgery and any inhibitory effects on the function of osteoblasts may affect the integration of the orthopedic implant into the bone postsurgery. It is therefore essential to consider the duration of an orthopedic surgical procedure and establish the effects of 405-nm light on osteoblast function during this potential exposure. Discussion with surgeons has revealed that the duration of routine arthroplasty surgeries was between 1 and $2 \mathrm{~h}$, although a complex revision may take up to $4 \mathrm{~h}$. Previous studies on fibroblasts for wound healing have shown that 405-nm light had no significant effect on cell viability when exposed to a dose of $18 \mathrm{~J} / \mathrm{cm}^{2}$ $\left(5 \mathrm{~mW} / \mathrm{cm}^{2}\right.$ for $\left.1 \mathrm{~h}\right)$, while a substantial decline in cell viability was observed at a dose of $54 \mathrm{~J} / \mathrm{cm}^{2}\left(15 \mathrm{~mW} / \mathrm{cm}^{2}\right.$ for $\left.1 \mathrm{~h}\right){ }^{7}$ It has also been found that exposing osteoblasts to 405-nm light with a dose of $54 \mathrm{~J} / \mathrm{cm}^{2}\left(5 \mathrm{~mW} / \mathrm{cm}^{2}\right.$ for $\left.3 \mathrm{~h}\right)$ had a detrimental effect on cell viability. ${ }^{9}$ Hence, the aim of this study was to establish whether the adverse effects of 405-nm light seen on mammalian cells were dose dependent, to determine a damage threshold of exposure of osteoblasts to 405-nm light, and to find out whether doses below the damage threshold can exert a bactericidal effect on clinically relevant pathogenic bacteria. Demonstration of these key parameters would be an essential step toward assessing whether this novel technology could be developed and applied for localized decontamination of the patient environment during arthroplasty surgeries. 


\section{Methods and Materials}

\subsection{Mammalian Cell Study}

Immortalized osteoblast (OST 5) cells isolated by SV40 transfection of neonatal rat calvarial osteoblasts were chosen for use in the experiments. The cells were cultured as monolayers using Dulbecco's modified Eagle's medium (DMEM) containing 10\% $\mathrm{v} / \mathrm{v}$ fetal calf serum in an atmosphere of $5 \% \mathrm{CO}_{2}$ in air at $37^{\circ} \mathrm{C}$.

The 405-nm light system used in this study consisted of an array of nine 405-nm light-emitting diodes (LEDs) (GE Illumination), with a full-width half-maximum of $20 \mathrm{~nm}$. The LEDs were arranged in a $3 \times 3$ grid pattern $(6 \mathrm{~cm} \times 6 \mathrm{~cm})$, and attached to a heat sink for thermal management, thus preventing sample heating during light exposure. The heat sink was supported by two pillars above a molded base designed to fit a multiplate in order to fix the position of the treatment plates directly below the LEDs. The light source was set at a height of $8 \mathrm{~cm}$ above the multiwell plate. The middle 4 wells in a 24-well plate and the middle 16 wells in a 96-well plate were used for cell exposures. Cells were seeded at a seeding density of $5 \times$ $10^{3}$ cells $/ \mathrm{cm}^{2}$ in a 24 -well plate and $2 \times 10^{4}$ cells $/ \mathrm{cm}^{2}$ in a 96-well plate and left in the incubator overnight at $37^{\circ} \mathrm{C}$.

To investigate the dose-dependent effects of 405-nm light on the osteoblasts, the samples were exposed to light in $1 \mathrm{ml}$ Dulbecco's phosphate-buffered saline (DPBS), inside an incubator at $37^{\circ} \mathrm{C}$ and $5 \% \mathrm{CO}_{2}$, at a low dose of $18 \mathrm{~J} / \mathrm{cm}^{2}$ and a high dose of $54 \mathrm{~J} / \mathrm{cm}^{2}$ using varying irradiance/exposure regimes (Table 1). Dose $\left(\mathrm{J} / \mathrm{cm}^{2}\right)$ is calculated according to the equation:

$E^{\prime}=P^{\prime} t$

where $E^{\prime}$ is the dose (energy density) in $\mathrm{J} / \mathrm{cm}^{2}, P^{\prime}$ is the irradiance (power density) in $\mathrm{W} / \mathrm{cm}^{2}$, and $t$ is the time in seconds.

Unexposed controls were treated in the same way. After the stipulated exposure time, the DPBS solution was removed, $1 \mathrm{ml}$ of DMEM was added to the wells, and the cells were incubated for 48 or $72 \mathrm{~h}$ before assessing the cell population using crystal violet staining and Lowry protein assay. ${ }^{10}$

Table 1 Irradiance levels and exposure times used to apply low dose $\left(18 \mathrm{~J} / \mathrm{cm}^{2}\right)$ and high dose $\left(54 \mathrm{~J} / \mathrm{cm}^{2}\right) 405-\mathrm{nm}$ light to osteoblasts.

\begin{tabular}{lcc}
$\begin{array}{l}\text { Period of exposure } \\
\text { (minutes) }\end{array}$ & $\begin{array}{l}\text { Irradiances } \\
\left(\mathrm{mW} / \mathrm{cm}^{2}\right)\end{array}$ & $\begin{array}{c}\text { Dose } \\
\left(\mathrm{J} / \mathrm{cm}^{2}\right)\end{array}$ \\
\hline
\end{tabular}

Low Dose exposures

\begin{tabular}{lcc}
60 & 5 & 18 \\
20 & 2.5 & 18 \\
180 & 1.7 & 18 \\
240 & 1.25 & 18 \\
High Dose exposures & 15 & \\
60 & 7.5 & 54 \\
120 & 5 & 54 \\
180 & 3.75 & 54 \\
240 & & 54 \\
\hline
\end{tabular}

To establish a damage threshold for osteoblast cells, samples were exposed to $405-\mathrm{nm}$ light at an irradiance of $5 \mathrm{~mW} / \mathrm{cm}^{2}$ in $1 \mathrm{ml}$ DPBS for increasing time periods $(60,90,120$, and $150 \mathrm{~min}$ corresponding to doses of $18,27,36$, and $45 \mathrm{~J} / \mathrm{cm}^{2}$ ) inside an incubator at $37^{\circ} \mathrm{C}$ and $5 \% \mathrm{CO}_{2}$. Unexposed controls were treated in the same way. After the stipulated exposure time, the DPBS was removed, $1 \mathrm{ml}$ DMEM was added to wells, and the cells were incubated for 48 or $72 \mathrm{~h}$ before carrying out the following assays.

To measure cell viability, the MTT (3-(4,5-dimethylthiazol2-yl)-2,5-diphenyltetrazolium bromide) assay was carried out as described by Ho et al. ${ }^{11}$ Cell function was measured using the alkaline phosphatase (ALP) assay as described by McDonald et $\mathrm{al}^{7}$ The bromodeoxyuridine (BrdU) assay was carried out to measure the cell proliferation rate postlight exposure using QIA 58 BrdU cell proliferation assay kit (CalbiochemMerckmillipore) as described by the manufacturer.

Live/dead staining of the cells was carried out using acridine orange (AO; live cells stain green) and propidium iodide (PI; dead cells stain red). The cells were stained with phalloidinFITC (green stain for actin; Sigma-Aldrich Company Ltd., UK)/ DAPI (blue nuclear stain; Life technologies, Paisley, Scotland, UK) to study the cytoskeletal actin structures of cells.

For microscopy, cells were seeded on glass coverslips (13-mm diameter) at $5 \times 10^{3} / \mathrm{cm}^{2}$ and viewed under a Zeiss AxioImager $\mathrm{Z} 1$ fluorescent microscope using a $20 \times$ wet lens $(\mathrm{NA}=0.5)$.

\subsection{Bacterial Study}

The bacteria used in this study were $S$. aureus NCTC 4135, Escherichia coli NCTC 9001, Pseudomonas aeruginosa LMG 9009, Klebsiella pneumoniae NCTC 09633, Staphylococcus epidermidis LMG 10474, and Acinetobacter baumannii LMG 1041 (NCTC, National Collection of Type Cultures, Collindale, UK; LMG, Laboratorium voor Microbiologie, Universiteit Gent, Belgium). Bacteria were cultured in nutrient broth (Oxoid, $\mathrm{UK}$ ) at $37^{\circ} \mathrm{C}$ for $18 \mathrm{~h}$ under rotary conditions (120 rpm). Broths were centrifuged at $4300 \mathrm{rpm}$ for $10 \mathrm{~min}$, and the cell pellet was resuspended in PBS. The cell suspension was then diluted in PBS to obtain a concentration of $10^{3}$ colony forming units $(\mathrm{CFU}) / \mathrm{ml}$. Samples $(100 \mu \mathrm{l})$ were then spread onto $55 \mathrm{~mm}$ agar plates, with approximately 150 to $300 \mathrm{CFU} /$ plate, and seeded agar plates were then exposed to 405-nm light at an irradiance of $5 \mathrm{~mW} / \mathrm{cm}^{2}$ for increasing time periods $(15,30,60,90$, and 120 min corresponding to doses of 4.5, 9, 18, 27, and $36 \mathrm{~J} / \mathrm{cm}^{2}$ ). Postexposure, plates were incubated at $37^{\circ} \mathrm{C}$ for $24 \mathrm{~h}$ before enumeration of the viable CFU/plate. Results are reported as \% surviving CFU/plate as compared to nonexposed control samples.

\section{Results and Discussion}

Data in Fig. 1 show that exposure of cells to $18 \mathrm{~J} / \mathrm{cm}^{2} 405-\mathrm{nm}$ light using different irradiance/exposure period regimes caused no significant difference in the crystal violet staining or protein concentration between the control and the treated samples after 48- and 72-h posttreatment periods. In contrast, a significant difference was evident between the control and the $405 \mathrm{~nm}$ treated samples exposed to higher doses of $54 \mathrm{~J} / \mathrm{cm}^{2}$ irrespective of how the dose was administered. These results confirm that the effect of 405-nm light on mammalian cells is dose dependent. 

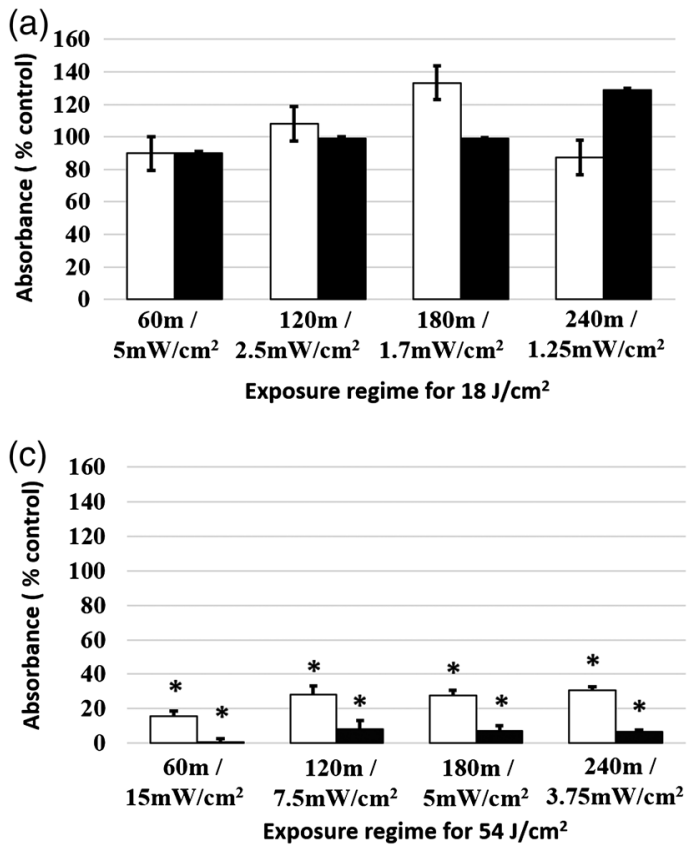

$405 \mathrm{~nm}$ treated -48
hour post treatment

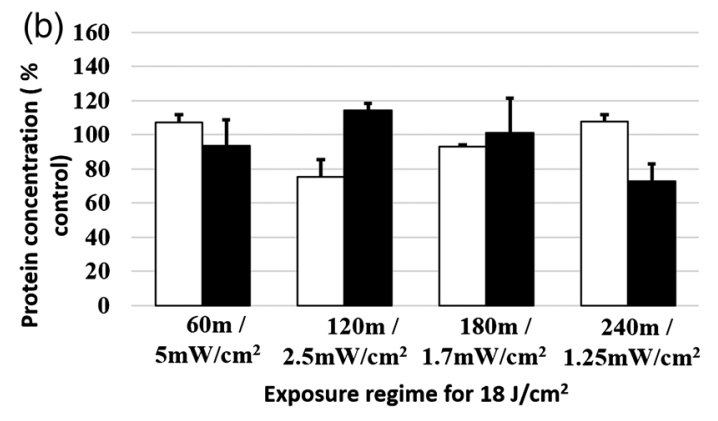

(d)

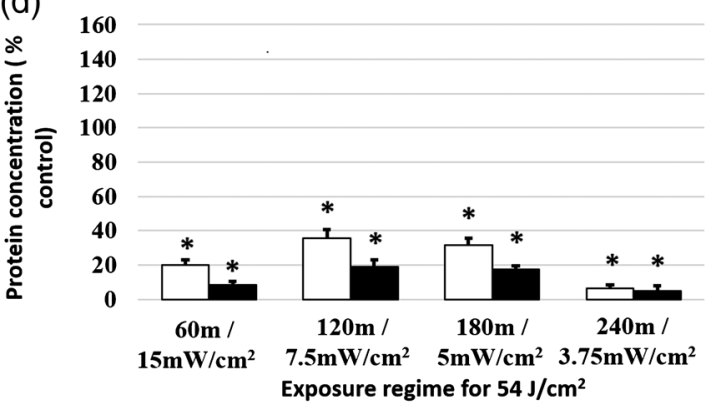

$405 \mathrm{~nm}$ treated -72

hour post treatment

Fig. 1 Crystal violet staining and protein content of osteoblasts exposed to different doses of 405-nm light. (a) Crystal violet absorbance (\% control), (b) protein concentration (\% control) of rat osteoblasts exposed to $405-\mathrm{nm}$ light at a low dose of $18 \mathrm{~J} / \mathrm{cm}^{2}$ and (c) crystal violet absorbance (\% control), (d) protein concentration (\% control) of rat osteoblasts exposed to a high dose of $54 \mathrm{~J} / \mathrm{cm}^{2}$. Doses were achieved using different irradiance/exposure time regimes, and were followed by either 48 or 72 -h posttreatment periods. Results are means of $n=8 \pm$ SEM. *Statistically different using unpaired Student's $t$ test comparing control and light treated samples, $p<0.05$.

Data in Fig. 2 show that cells exposed to doses of 18, 27, and $36 \mathrm{~J} / \mathrm{cm}^{2}\left(5 \mathrm{~mW} / \mathrm{cm}^{2}\right.$ for 60,90 , and $120 \mathrm{~min}$, respectively) exhibited no significant effect on the MTT reduction, the ALP activity or the cell proliferation rate as measured by the BrdU method. In contrast, cells exposed to doses above $36 \mathrm{~J} / \mathrm{cm}^{2}$ $\left(5 \mathrm{~mW} / \mathrm{cm}^{2}\right.$ for more than $\left.120 \mathrm{~min}\right)$ showed a significant decrease in all the parameters of cell function.

$\mathrm{AO}$ and PI dyes were used in this study to differentiate live cells, apoptotic and necrotic cells and study the viability of osteoblasts after 48- and 72-h postlight exposure periods. All live nucleated cells fluoresce green, early apoptotic cells fluoresce bright green, late apoptotic cells fluoresce orange, and all dead nucleated cells fluoresce red. After both 48- and 72-h culture postexposure to light, more apoptotic and dead cells were observed following $150 \mathrm{~min}\left(45 \mathrm{~J} / \mathrm{cm}^{2}\right)$ exposure compared to $120 \mathrm{~min}\left(36 \mathrm{~J} / \mathrm{cm}^{2}\right)$ exposure to $5 \mathrm{~mW} / \mathrm{cm}^{2} 405-\mathrm{nm}$ light (Fig. 3), confirming the findings with MTT. Staining of the actin with phalloidin-FITC showed that after exposure to $45 \mathrm{~J} / \mathrm{cm}^{2}$ light, the actin formed a ring around the cell membrane, and more cells rearranged themselves into a circular shape, when compared with the samples exposed to $36 \mathrm{~J} / \mathrm{cm}^{2}$ for both 48- and 72-h posttreatment period (Fig. 4). Accumulation of actin around the outer-cell perimeter is indicative of membranes being strengthened to prevent leakage of the cell contents and is a sign of apoptosis. At $48 \mathrm{~h}$ in culture postexposure to light, the cells show early apoptosis [Fig. 3(b)], but this damage appears to be repaired at $72 \mathrm{~h}$ in culture postexposure to light [Fig. 3(f)]. Exposure to 405-nm light may indeed cause sublethal damage to the cells, and further studies such as assessment of deoxyribose nucleic acid (DNA) integrity will be required.
The mammalian cell studies suggest that cell exposures to 405-nm HINS light for up to a dose of $36 \mathrm{~J} / \mathrm{cm}^{2}$ cause no observable effects on the cell viability, function, proliferation rate, and morphology using the techniques employed in this study. When investigating the comparative effects of 405-nm light exposure on bacterial cells, results demonstrate that doses up to $36 \mathrm{~J} / \mathrm{cm}^{2}$, which were found to have no impact on the mammalian cells, induce significant bactericidal effects. Results in Fig. 5 highlight the inactivation kinetics of a range of Gram-positive ( $S$. aureus, S. epidermidis) and Gram-negative (P. aeruginosa, A. baumannii, E. coli, K. pneumoniae) bacteria. The susceptibility of the organisms varied with $A$. baumannii proving most susceptible with $>98 \%$ kill achieved after exposure to $4.5 \mathrm{~J} / \mathrm{cm}^{2} \quad(p<0.001)$. Significant inactivation of all organisms was achieved by exposure to $18 \mathrm{~J} / \mathrm{cm}^{2}$ and between $99.5 \%$ to $100 \%$ inactivation of all species was shown after application of $36 \mathrm{~J} / \mathrm{cm}^{2}$. A previously published study reported the antibacterial effects of 405-nm light against these clinically relevant organisms, demonstrating their susceptibility at population densities of up to $9-\log _{10} \mathrm{CFU} / \mathrm{ml}$ in liquid suspension ${ }^{3}$ however, the present study uses light doses and surface-seeded bacterial contaminants at population densities $\left(\sim 10^{2} \mathrm{CFU} /\right.$ plate $)$ that are more relevant to practical clinical environmental decontamination applications, ${ }^{4}$ as has been demonstrated in a previous work. ${ }^{9}$ The present study confirms, by direct comparison, the selective detrimental effect that light of this wavelength can have on infection-causing organisms in comparison to osteoblasts.

The antibacterial effect of 405-nm light is not thought to be mediated through direct DNA crosslinking, unlike that of UV light. ${ }^{12}$ Instead, the $405 \mathrm{~nm}$ violet-blue light inactivation effect 


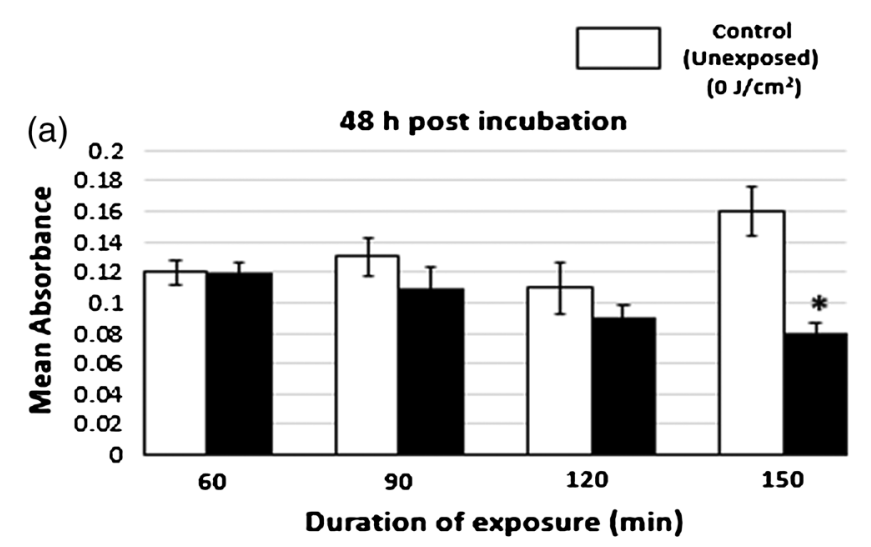

$5 \mathrm{mw} / \mathrm{cm}^{2}$ of $405 \mathrm{~nm}$ light
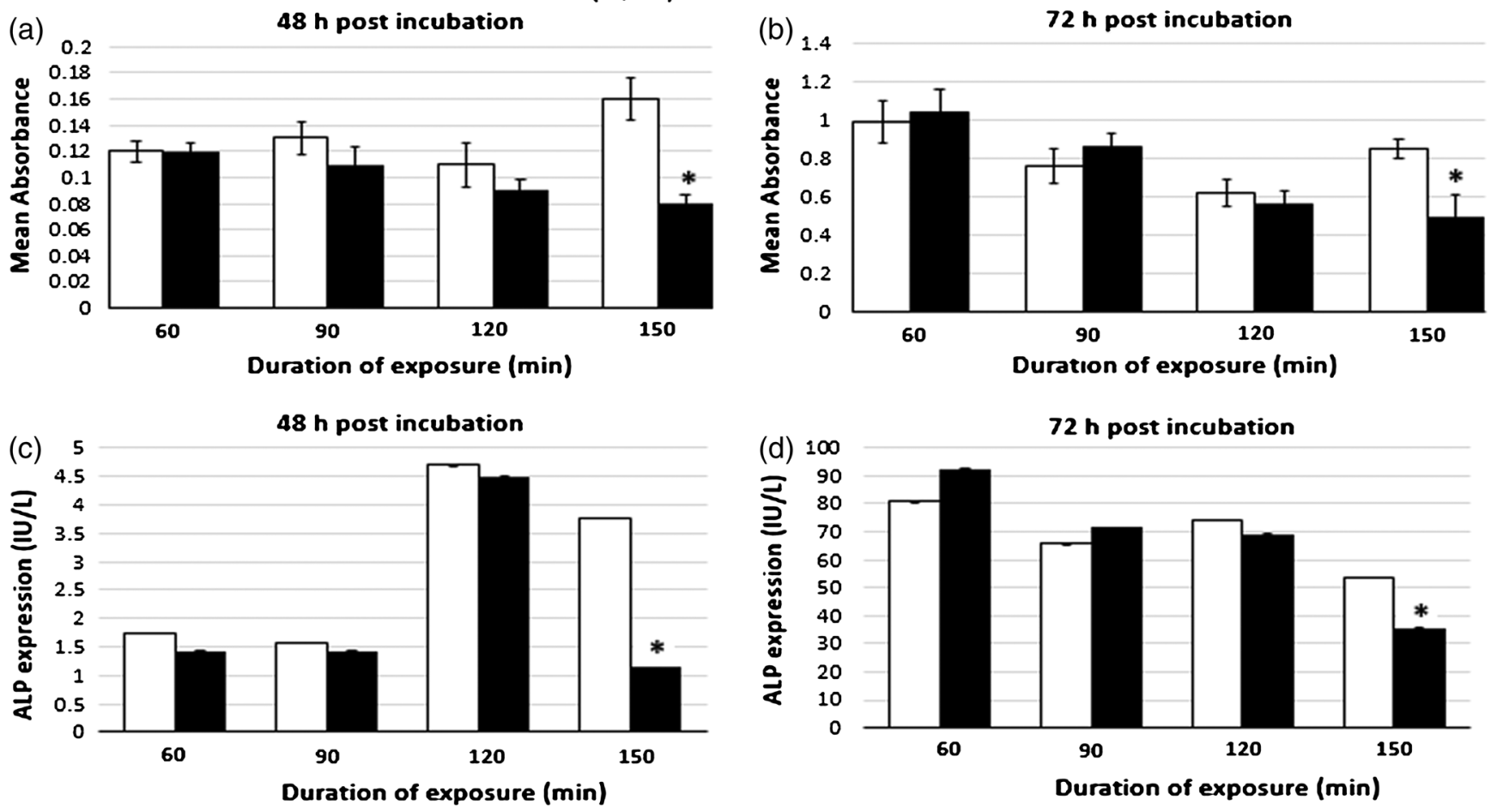

$\rightarrow-$ Control (Unexposed) $\left(0 \mathrm{~J} / \mathrm{cm}^{2}\right)$
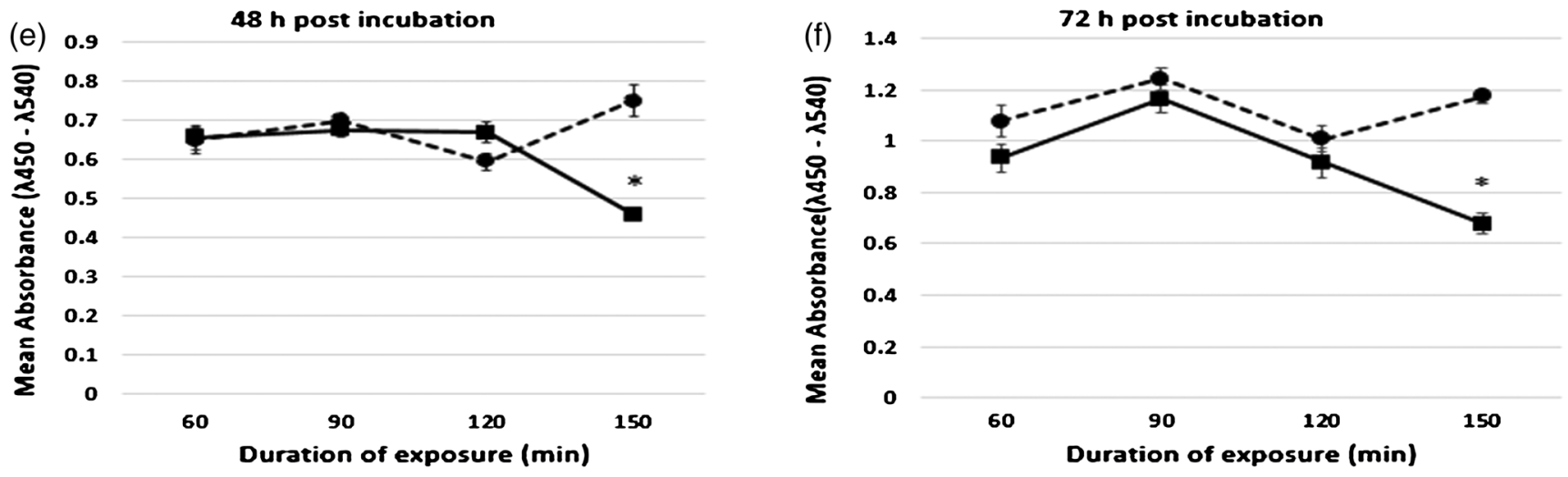

Fig. 2 MTT reduction, ALP activity, and cell proliferation in osteoblasts exposed to different doses of 405nm light. (a) and (b) MTT reduction (mean absorbance \pm SEM, $n=8$ ), (c) and (d) ALP activity (IU/L \pm SEM, $n=8$ ), and (e) and (f) BrdU absorbance (mean \pm SEM, $n=8$ ) of rat osteoblasts exposed to 405 -nm light doses of $18,27,36$, and $45 \mathrm{~J} / \mathrm{cm}^{2}\left(5 \mathrm{~mW} / \mathrm{cm}^{2}\right.$ for $60,90,120$, and $150 \mathrm{~min}$, respectively) followed by 48- (left) and 72-h (right) posttreatment period. *Statistically different, using unpaired Student's $t$-test comparing control and light treated samples, $p<0.05$.

is considered to be caused by the excitation of intracellular photosensitive porphyrin molecules, which results in the production of reactive oxygen species, inducing oxidative damage and, consequently, cell death. ${ }^{3,13-15}$ Indeed, previous studies have detected endogenous porphyrins within $S$. aureus, ${ }^{15}$ P. aeruginosa,${ }^{14}$ and $A$. baumannii, ${ }^{16}$ and implicated these violet-blue light sensitive molecules in the inactivation mechanism. In addition, a study by Lipovsky et al. ${ }^{15}$ compared the sensitivity of two strains of $S$. aureus and found that the more light-sensitive strain contained 10-fold more endogenous porphyrins than the more resilient strain. Further evidence of the involvement of porphyrins in the inactivation process was provided by Nitzan et al., who demonstrated that bacterial susceptibility to violet-blue light inactivation can be increased when exogenous $\delta$-aminolevulinic acid (ALA), the precursor of the porphyrin biosynthesis pathway, is added in order to amplify the levels of endogenous porphyrins within the bacterial cells. ${ }^{15-17}$ Since ROS are considered 4 to cause widespread oxidative damage to bacterial cells and the mechanism of action is not site specific, as is the case with many antibiotics, this explains not only the broad spectrum antimicrobial efficacy of 405-nm light but also why highly antibiotic resistant species such as Acinetobacter baumanii show no greater resistance to $405-\mathrm{nm}$ light than nonantibiotic resistant bacteria. Bacterial cells have also been shown to have much 

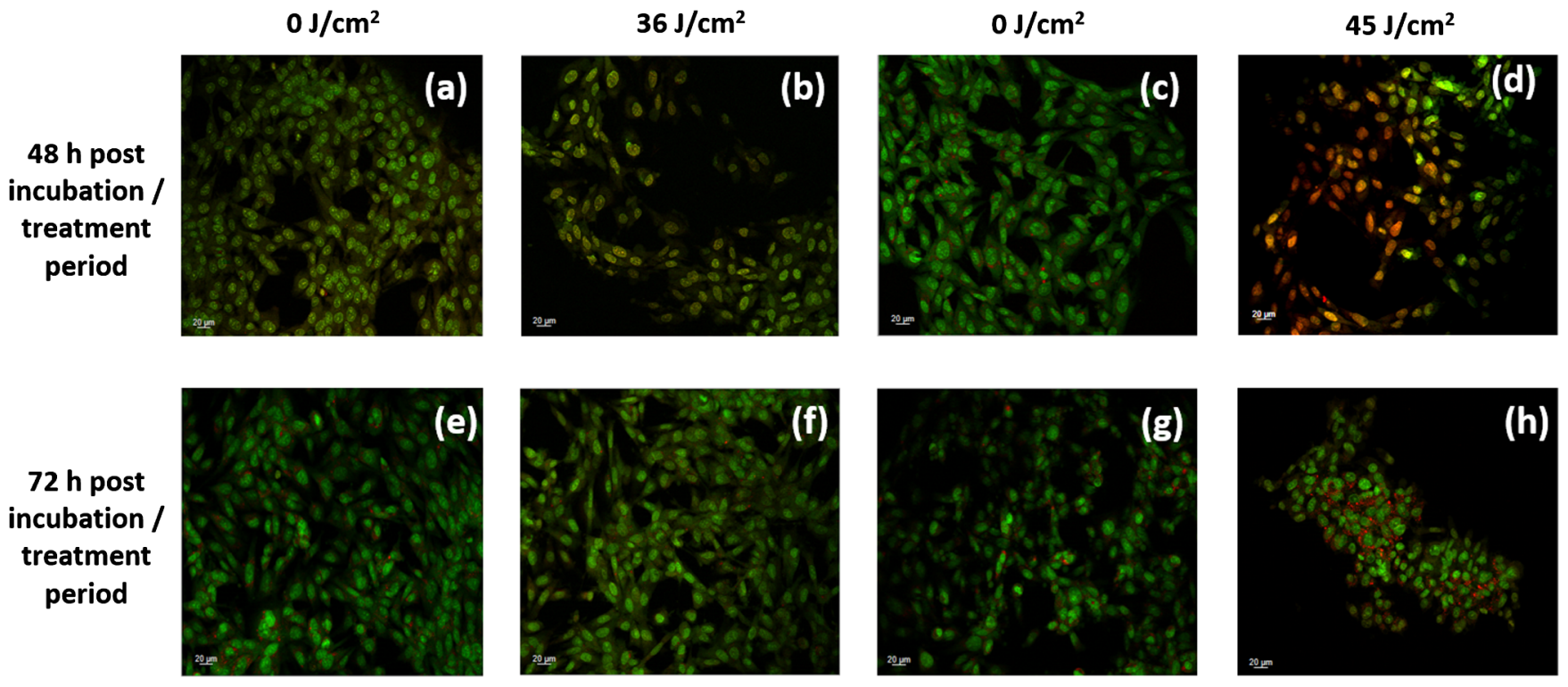

Fig. 3 The cell viability of osteoblast cells after exposure to $5 \mathrm{~mW} / \mathrm{cm}^{2}$ of $405-\mathrm{nm}$ light. [(a) and (c) Control $\left(0 \mathrm{~J} / \mathrm{cm}^{2}\right.$ for 120 and $150 \mathrm{~min}$, respectively for a 48-h postincubation period), (e) and (g) control ( $0 \mathrm{~J} / \mathrm{cm}^{2}$ for 120 and $150 \mathrm{~min}$, respectively for a 72-h postincubation period). (b) and (d) Exposure for $120 \mathrm{~min}\left(36 \mathrm{~J} / \mathrm{cm}^{2}\right)$ and $150 \mathrm{~min}\left(45 \mathrm{~J} / \mathrm{cm}^{2}\right)$, respectively, for a 48 -h posttreatment period and (f) and (h) exposure for $120 \mathrm{~min}\left(36 \mathrm{~J} / \mathrm{cm}^{2}\right)$ and $150 \mathrm{~min}\left(45 \mathrm{~J} / \mathrm{cm}^{2}\right)$, respectively, for a $72-\mathrm{h}$ posttreatment period).] Acridine orange stains live cells green, early and late apoptotic cells bright green and orange, respectively, and propidium iodide stains dead cells red.

greater sensitivity than mammalian cells to violet-blue light in the region of $405 \mathrm{~nm} .{ }^{9,14}$ Low levels of antioxidant defence enzymes in certain bacteria have been implicated as a possible reason for this, ${ }^{19}$ and as such are more susceptible to ROS mediated oxidative damage. In contrast, most mammalian cells are well equipped to survive in high oxygen conditions, and contain ample cytoprotective mechanisms such as superoxide dismutase, catalase, and glutathione peroxidise. ${ }^{19}$

These findings thus highlight the potential for development of 405-nm light for inactivation of bacterial contaminants around surgical sites. Exposure to $405-\mathrm{nm}$ light has also been proven to cause no adverse effects on wound healing, ${ }^{7}$ thus
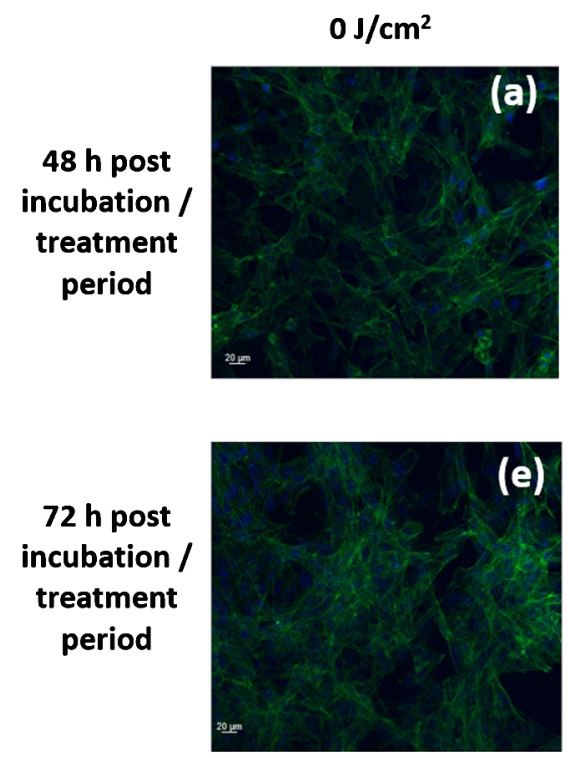

$36 \mathrm{~J} / \mathrm{cm}^{2}$
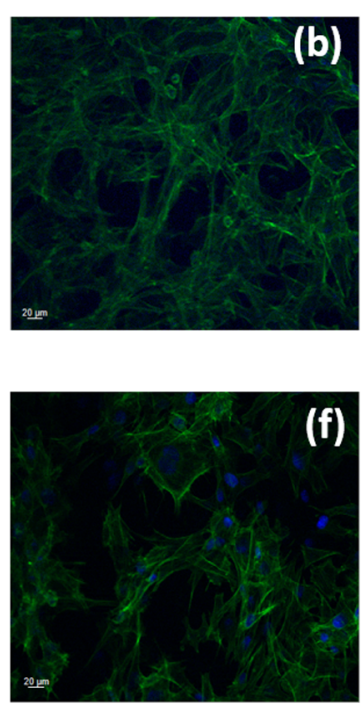

$0 \mathrm{~J} / \mathrm{cm}^{2}$
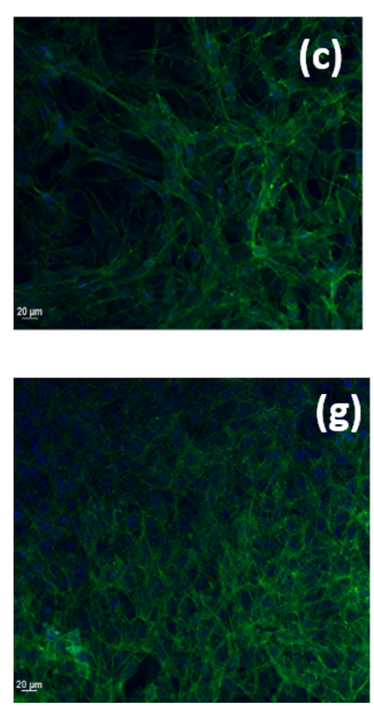

$45 \mathrm{~J} / \mathrm{cm}^{2}$
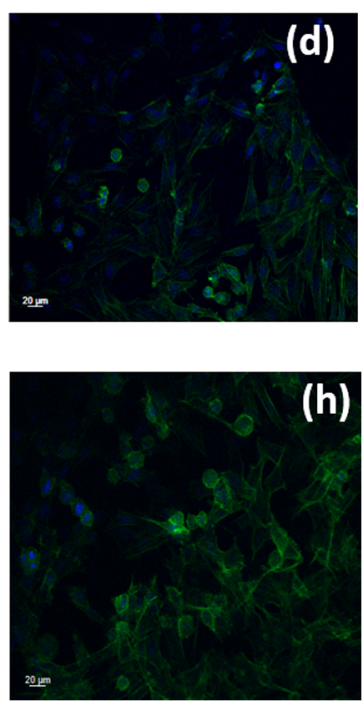

Fig. 4 The cell morphology of osteoblast cells after exposure to $5 \mathrm{~mW} / \mathrm{cm}^{2}$ of $405-\mathrm{nm}$ light. [(a) and (c) Control $\left(0 \mathrm{~J} / \mathrm{cm}^{2}\right.$ for 120 and $150 \mathrm{~min}$, respectively, for a 48-h postincubation period), (e) and (g) control $\left(0 \mathrm{~J} / \mathrm{cm}^{2}\right.$ for 120 and $150 \mathrm{~min}$, respectively, for a $72-\mathrm{h}$ postincubation period). (b) and (d) exposure for $120 \mathrm{~min}\left(36 \mathrm{~J} / \mathrm{cm}^{2}\right)$ and $150 \mathrm{~min}\left(45 \mathrm{~J} / \mathrm{cm}^{2}\right)$, respectively, for a 48-h posttreatment period and $(\mathrm{f})$ and $(\mathrm{h})$ exposure for $120 \mathrm{~min}\left(36 \mathrm{~J} / \mathrm{cm}^{2}\right)$ and $150 \mathrm{~min}\left(45 \mathrm{~J} / \mathrm{cm}^{2}\right)$, respectively, for a $72-\mathrm{h}$ posttreatment period).] Phalloidin-FITC stains the cytoskeleton green and DAPI stains the nucleus blue. 


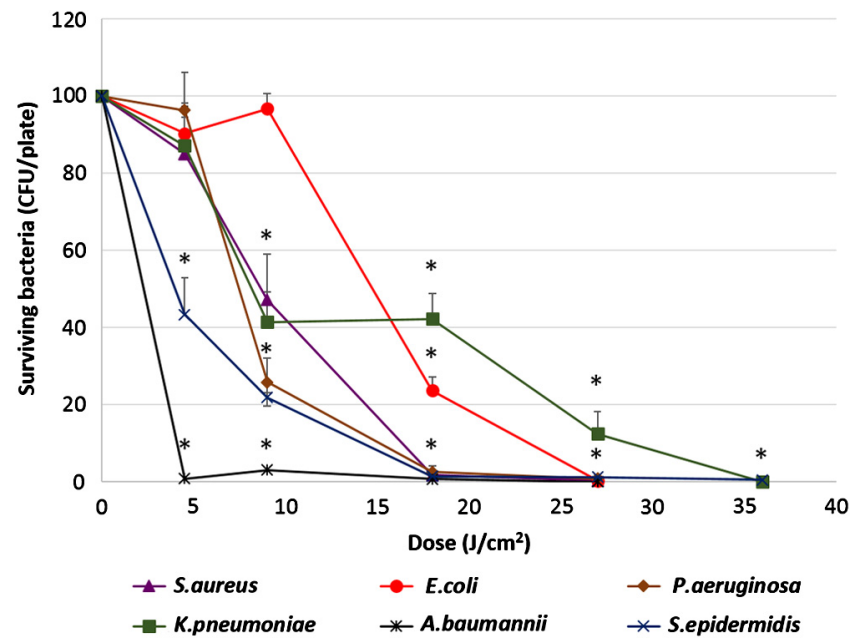

Fig. 5 Survival of a range of surface seeded clinically relevant bacterial pathogens exposed to 405-nm HINS light at doses ranging from 4.5 to $36 \mathrm{~J} / \mathrm{cm}^{2}$. Results are means of $n=4 \pm$ SEM. *Statistically different, using unpaired Student's $t$-test comparing control and light treated samples, $p<0.05$

providing further evidence for potential clinical application of this disinfection technology.

Importantly, the dose-dependent effects of 405-nm light on osteoblast cells suggest that the dose of $36 \mathrm{~J} / \mathrm{cm}^{2}$, which may be achieved by applying different irradiances for varying time periods (e.g., $10 \mathrm{~mW} / \mathrm{cm}^{2}$ for $1 \mathrm{~h}, 5 \mathrm{~mW} / \mathrm{cm}^{2}$ for $2 \mathrm{~h}$, $3.3 \mathrm{~mW} / \mathrm{cm}^{2}$ for $3 \mathrm{~h}$, and $2.5 \mathrm{~mW} / \mathrm{cm}^{2}$ for $4 \mathrm{~h}$ ), does not cause detectable damage to mammalian cells, regardless of how the dose is applied. These findings are significant, and should provide a basis for the development of light sources which could be applied practically within operating theaters at levels appropriate for the typical operating times relevant to arthroplasty surgery.

Further safety advantages of light of this wavelength relate to the photon energy of 405-nm light. The depth of penetration of visible light into tissue increases with wavelength ${ }^{20}$ and the penetrability of 405-nm light, which although greater than that of UV light, is low and will not penetrate deeply into bone; particularly when compared to light of a longer wavelength, e.g., 690-nm laser light. ${ }^{21}$ Also, the 405-nm intensities suggested for use during surgical exposures would be low; therefore, theater personnel are unlikely to require protection from these visible violet-blue light wavelengths. This is unlike UV light which, due to the high photon energy and associated detrimental health effects, is normally only used in the absence of people. There have been limited attempts to utilize UV light during surgical procedures but these have required operating staff to wear protective clothing during exposure. ${ }^{22,23}$

\section{Summary}

A 405-nm HINS light has proven to have strong antimicrobial effects against a variety of medically significant bacteria at a dose level of $36 \mathrm{~J} / \mathrm{cm}^{2}$. Conversely, mammalian cell studies found that the osteoblasts appear healthy when exposed to doses up to $36 \mathrm{~J} / \mathrm{cm}^{2}$; at higher doses, there is a negative impact on cell viability, function, and proliferation rate. The results obtained from the application of low dose and high dose light using a range of irradiance/exposure time regimes have demonstrated that the effects of $405-\mathrm{nm}$ light on osteoblast cells are dose dependent. This study has established a dose-dependent level at which there is a differential sensitivity to the effects of 405-nm light between osteoblasts and bacteria; exposure of mammalian cells up to a dose of $36 \mathrm{~J} / \mathrm{cm}^{2}$ does not cause any observable effect on osteoblast viability. At this dose, the 405-nm light is still bactericidal indicating that there is potential to develop the technology for decontamination of the environment around patients during arthroplasty surgery.

\section{Acknowledgments}

P.R. is supported by a DTC studentship from the Engineering and Physical Sciences Research Council. The authors are grateful for the help of Mrs. Katie Henderson with mammalian cell culture.

\section{References}

1. M. Albrecht, R. Gauthier, and D. Leaper, "Forced-air warming: a source of airborne contamination in the operating room?," Orthop. Rev. (Pavia) 1(2), e28 (2009).

2. R. W. Loftus et al., "Hand contamination of anesthesia providers is an important risk factor for intraoperative bacterial transmission," Anesth. Analg. 112, 98-105 (2011).

3. M. Maclean et al., "Inactivation of bacterial pathogens following exposure to light from a 405-nm LED array," Appl. Environ. Microbiol. 75(7), 1932-1937 (2009).

4. M. Maclean et al., "Environmental decontamination of a hospital isolation room using high-intensity narrow-spectrum light," J. Hosp. Infect. 76(3), 247-251 (2010).

5. H. Hamilton and J. Jamieson, "Deep infection in total hip arthroplasty," Can. J. Surg. 51(2), 111-117 (2008).

6. N. Davis et al., "Intraoperative bacterial contamination in operations for joint replacement," J. Bone Joint Surg. Br. 81(5), 886-889 (1999).

7. R. McDonald et al., "Effect of $405 \mathrm{~nm}$ high-intensity narrow-spectrum light on fibroblast populated collagen lattices: an in vitro model of wound healing," J. Biomed. Opt. 16(4), 048003 (2011).

8. S. Smith et al., "Exposure of 3T3 mouse fibroblasts and collagen to high intensity blue light," in IFMBE Proc. 13th Int. Conf. on Biomedical Engineering, Vol. 23, pp. 1352-1355, Singapore (2009).

9. R. McDonald et al., "405 nm light exposure of osteoblasts and inactivation of bacterial isolates from arthroplasty patients: potential for new disinfection applications?," Eur. Cell Mater. 25, 204-214 (2013).

10. O. H. Lowry et al., "Protein measurement with the folin phenol reagent," J. Biol. Chem. 193(1), 265-275 (1951).

11. G. Ho et al., "Low-level laser therapy on tissue-engineered skin substitutes: effect on the proliferation rate of 3 T3 mouse fibroblast cells," Proc. SPIE 5610, 124-134 (2004).

12. K. Oguma et al., "Determination of pyrimidine dimmers in Escherichia coli and Cryptosporidium parvum during UV light inactivation, photoreactivation, and dark repair," Appl. Environ. Microbiol. 67(10), 4630-4637 (2001).

13. R. Lubart et al., "A possible mechanism for the bactericidal effect of visible light," Laser Ther. 20(1), 17-22 (2011).

14. T. Dai et al., "Blue light rescues mice from potentially fatal Pseudomonas aeruginosa burn infection: efficacy, safety, and mechanism of action," Antimicrob. Agents Chemother. 57(3), 1238 (2013).

15. A. Lipovsky et al., "Visible light-induced killing of bacteria as a function of wavelength: implication for wound healing," Lasers Surg. Med. 42, 467-472 (2010).

16. Y. Zhang et al., "Antimicrobial blue light therapy for multidrug-resistant Acinetobacter baumannii infection in a mouse burn model: implications for prophylaxis and treatment of combat-related wound infections," J. Infect. Dis. 209, 1963-1971 (2014).

17. Y. Nitzan and M. Kauffman, "Endogenous porphyrin production in bacteria by $\delta$-aminolaevulinic acid and subsequent bacterial photoeradication," Lasers Med. Sci. 14, 269-277 (1999).

18. Y. Nitzan et al., "ALA induced photodynamic effects on Gram positive and negative bacteria," Photochem. Photobiol. Sci. 3(5), 430-435 (2004). 
19. B. Halliwell and J. M. C. Gutteridge, "Antioxidant defences," Chapter 3 in Free Radicals in Biology and Medicine, pp. 105-245, Oxford University Press, Oxford (2001).

20. E. Sternberg and D. Dolphin, "Porphyrin-based photosensitizers for use in photodynamic therapy," Tetrahedron 54(17), 4151-4202 (1998).

21. S. K. Bisland and S. Burch, "Photodynamic therapy of diseased bone," Photodiagn. Photodyn. Therapy 3(3), 147-155 (2006).
22. P. E. Gosden, A. P. MacGowan, and G. C. Bannister, "Importance of air quality and related factors in the prevention of infection in orthopaedic implant surgery," J. Hosp. Infect. 39(3), 173-180 (1998).

23. G. J. S. Taylor, G. C. Bannister, and J. P. Leeming, "Wound disinfection with ultraviolet radiation," J. Hosp. Infect. 30(2), 85-93 (1995).

Biographies of the authors are not available. 